\title{
Deprem Yükü Etkisindeki Betonarme Yapıların Tasarımında Yapı-Zemin Etkileşiminin İncelenmesi
}

\author{
Saffet Kılıçer1, ${ }^{*}$, Korhan Özgan² \\ ${ }^{1}$ Artvin Çoruh Üniversitesi, Mühendislik Fakültesi, Çevre Mühendisliği Bölümü, 08100, Artvin. \\ ${ }^{2}$ Karadeniz Teknik Üniversitesi, Mühendislik Fakültesi, Inşaat Mühendisliği Bölümü, 61080, Trabzon.
}

\section{Özet}

Ülkemizde en çok rastlanan doğal afetlerden biri kuvvetli yer hareketi olan depremlerdir. Deprem yer sarsıntısının etkisi ile yapılara hasarlar verir. Deprem kuvvetini önceden tahmin ederek oluşacak hasarları en aza indirmek inşaat mühendisliği disiplini için büyük önem arz etmektedir. Yapı davranışını doğru anlamak depremi önceden tahmin etmek kadar önemlidir. Bu yüzden yapılar daha doğru ve daha gerçekçi modellenmelidir. Betonarme yapıların tasarımı genellikle yapı tabanda rijit kabul edilerek ya da zeminin elastik yaylar ile tanımlandığı ticari programlar kullanılarak yapılmaktadır. Bu çalışmada, 1999 Kocaeli deprem kaydı dikkate alınarak 12 katlı betonarme bir yapı örneği, rijit temel varsayımı, Winkler ve Geliştirilmiş Vlasov modelleri ile analiz edilmiştir. MATLAB'te yazılan bir ara yüz ile SAP2000 ve MATLAB programlarının eş zamanlı veri alı̧̧verişi sağlanmış ve bu sayede SAP2000 programının bünyesinde var olmayan Geliştirilmiş Vlasov Modeli entegre edilerek analizler gerçekleștirilebilmiştir. Analizlerden elde edilen yapı doğal titreşim periyodu, toplam taban kesme kuvveti, kolon eksenel kuvvetleri, her iki doğrultudaki eğilme momentleri ve kat ötelenmeleri farklı zemin modelleri için karşılaşıtırılmışıı. Çalışmanın sonunda zemin etkisinin betonarme yapıların taşıyıcı sistem tasarımında göz ardı edilemeyecek kadar önemli bir faktör olduğu görülmüştür.

\section{Anahtar Sözcükler}

Yapı Zemin Etkileşimi, Deprem, Geliştirilmiş Vlasov Modeli, Betonarme Yapı Tasarımı, SAP2000, OAPI

\section{Investigation of Soil-Structure Interaction for Design of Reinforced Concrete Structures under Earthquake Load}

\begin{abstract}
One of the most common natural disasters in our country is earthquakes with strong ground motion. Earthquake damages structures with the impact of ground shaking. Prediction of earthquake magnitude in advance is a great importance in the civil engineering discipline to minimize possible damages during the earthquake. Therefore, understanding of structural behavior correctly is as important as the estimation of the possible earthquake magnitude. For this reason, structures should be modeled accurately and realistically. Reinforced concrete structures are usually designed using commercial software defined either as rigid or with elastic springs at the base. In this study, considering the earthquake recording of 1999 Kocaeli, a 12-storey reinforced concrete structure was analyzed with rigid foundation assumption, Winkler and Modified Vlasov models. An interface was coded in MATLAB to exchange data between SAP2000 and MATLAB. Thanks to the interface, SAP2000 has gained the ability of performing analyses with modified Vlasov model. In this way, periods, base shear forces, column axial forces, column bending moments and lateral displacements of the structures were compared for each subsoil model. At the end of the study, it is observed that the effect of subsoil on the structural behavior is an indispensable design factor for the reinforced concrete structures.
\end{abstract}

Keywords

Soil-Structure Interaction, Earthquake, Modified Vlasov Model, Design of Reinforced Concrete Structures, SAP2000, OAPI

\section{Giriş}

Yapı zemin etkileşimi inşaat mühendisliği disiplininin her alanında karşımıza çıkmaktadır. Havaalanlarında, barajlarda, yüksek yapılarda, otoyollarda ya da yüksek silolarda zemin etkisinin yapı davranışına etkisi ihmal edilemeyecek düzeyde olmaktadır. Öte yandan depremler tamamen kendine özgü ve birçok değişkene bağlı doğal olaylar olduklarından projelendirilen bir yapının gelecekte nasıl bir depremin etkisinde kalacağını tahmin etmek oldukça güçtür. Yapıların, deprem esnasında, açığa çıkan enerjiden ne kadar etkileneceği ya da bu kuvvetli deprem hareketi karşısında nasıl davranacağı günümüzde hala araştırmacıların ilgisini çeken konulardan biridir. Zeminlerin ve yapıların deprem etkisindeki davranışııı belirlemek için, öncelikle zemin ortamının ve deprem etkisinin doğru tanımlanabilmesi gerekir. Belirli bir bölgedeki depremin etkisinin değerlendirilmesi için yüzeydeki kuvvetli yer hareketinin çeşitli şekillerde tanımlanması gereklidir. Pratikte yer hareketi 3 bileşen (doğu-batı, kuzey-güney, düşey bileşen) ile ölçülür. 
Meydana gelen kuvvetli yer hareketlerine ait ivme kayıtları aynı bölgede üst yapı tasarımı için proje mühendislerine önemli birer referans oluşturmaktadır. Bu kayıtları kullanan mühendisler üst yapı projelendirme esnasında bu ivme kayıtlarından yararlanarak yapının davranışını belirleyebilmektedirler. Ancak, deprem etkisinin yanında zeminin üst yapıya etkisi tam olarak bilinememekte olup halen araştırmacılar için merak konusudur. Zemin etkisindeki yapı davranışını doğru ve gerçekçi olarak anlayabilmek için literatürde bir, iki ve üç parametreli zemin modelleri bulunmaktadır. Her bir model yapıdan temeller aracılığıyla zemine aktarılan yüklerin zeminde oluşturacağı etkileri ve bu etkilerin yapıda oluşturacağı tepkileri kendi içerisinde farklı yaklaşımlarla hesaplamaktadır. Uygulamada, betonarme yapı tasarımı yapan mühendisler yapıyı tabanda ankastre gibi varsaymakta ya da bazı paket programlarda bulunan Winkler modeline göre tasarımını gerçekleştirmektedir.

Kolonların tabanda ankastre kabulü ile analizler yapıldığında, kolon mesnetlerinde meydana gelen iç kuvvetler, yapıdan bağımsız olarak oluşturulan temel modeline etkitilmektedir. Bu durumda zeminin yapıya hiçbir etkisinin olmadığı varsayılmakta ve zemin davranışı göz ardı edilmektedir. Yapıların gerçek davranışlarına uygun şekilde modellenmesinde zemininde dikkate alınarak çözümlemelerin yapılması gerekmektedir. Ticari paket programlarda kullanılan bir parametreli zemin modeli, Winkler modeli, yüklerin üst yapıdan zemine aktarılması sırasında zeminin, doğrudan yüklendikleri noktada şekil değiştirdiği komşu bölgelerde bu yüklemeden etkilenmediği varsayımına dayanır. Zemin süreksiz olarak kabul edilmekte, kayma etkileri dikkate alınmamakta ve bilinmesi gerek tek parametre olan yatak katsayısının nasıl hesaplanacağı hakkında kesin bir ifade bulunmamaktadır. Yatak katsayısı ancak zemin deneyleri ya da belirli tablolardan yararlanarak belirlenebilmektedir. Pasternak modeli, Hetenyi modeli ve Vlasov modeli iki parametreli zemin modellerindendir. Bu modeller zemin tabakasındaki kayma şekil değiştirmelerini de dikkate alan ikinci bir parametre içermektedirler. Böylelikle sadece yükün etkidiği nokta değil komşu yaylarda bu yükten etkilenmektedir. Üç parametreli zemin modellerinden biri olan Geliştirilmiş Vlasov modeli yay sabiti ve kayma parametresinin yanında zeminin malzeme özelliklerini dikkate alan üçüncü bir parametrede $(\gamma)$ hesaba katmaktadır. Bu sayede zemin parametreleri, zemin özellikleri ve yapının yer değiştirmesine bağlı olarak hesaplanabilmektedir (ÖZgan vd. 2016).

Yapı zemin dinamik etkileşimi üzerine birçok çalışma yapılmıştır. Bu çalışmalardan bazıları şu şekildedir; Erdik (1989) özellikle yumuşak zeminlere oturan yüksek ve rijit yapılarda deprem etkisi altında yapı-zemin etkileşiminin önemine vurgu yapmıs ve bu tip yapıların incelenmesine yönelik bir şartname önerisi de sunmuştur. Korkmaz ve Demir (2012) çalışmalarında zemin türü ve özelliklerinin yapı davranışını nasıl etkilediğini incelemiş ve bu amaçla doğrusal olmayan analizler gerçekleştirmiştir. Özgan vd. (2016) geliştirdikleri bir arayüz ile SAP2000 programında Geliştirilmiş Vlasov Modeli ile temsil edilen bir zemin-yapı modeli dikkate almışlardır. Eşdeğer deprem yükü hesabını kullanarak elde ettikleri doğal periyot, taban kesme kuvveti, kolon eksenel kuvvetleri, kolon eğilme momentleri ve kolonların boyuna donatı oranları gibi parametreleri farklı zemin modelleri için karşılaştırmışlardır. Avcıoğlu ve Orakdöğen (2015) geliştirdikleri bir bilgisayar yazılımı aracıllğ̆ ile deprem etkisinde zemin parametrelerinin değişimini ve komşu binaların deprem etkileri altında birbirleri ile olan etkileşimlerini araştırmışlardır. Deprem hesabında zaman tanım alanında hesap yöntemi kullanmışlardır. Bu amaçla seçilen yapı modelleri, geliştirilen program yardımı ile çözülmüş ve daha önce genel amaçlı bir bilgisayar programı ile çözülen örnekte söz konusu parametrenin hesaplar üzerindeki etkisi tartışılmıştır. Livaoğlu ve Doğangün (2003) farklı taşıyıcı sisteme sahip ayaklı depoların değişik zemin sınıfları için deprem davranışını inceleyerek depreme göre yapısal çözümlemede mod birleştirme yöntemini kullanmışlardır. Ionescu vd. (2013) üç boyutlu bir yapıyı ANSYS programı kullanarak çözmüşler ve yapı-zemin dinamik etkileşimi üzerine çalışışlardır. Analizlerinde Boussinesq zemin modelini kullanmışlardır. Kılıçer (2016) farklı zemin modellerini dikkate alarak zemin parametreleri, kolon iç kuvvetleri, temel düşey yer değiştirmeleri gibi parametrelerin değişimini incelemiş̧tir.

$\mathrm{Bu}$ çalışmada seçilen yapı modelinin dinamik analizi SAP2000 paket programı kullanılarak yapılmıştır. Yapının deprem hesabı için Türk Deprem Yönetmeliğinde (URL-1 2017) önerilen dinamik yöntemlerden zaman tanım alanında analiz yöntemi kullanılmış ve Yarımca-Petkim istasyonundan alınan 17 Ağustos 1999 Kocaeli depremine ait ivme kayıtları dikkate alınmıştır. Literatürde daha gerçekçi bir zemin modeli olarak nitelenen Geliştirilmiş Vlasov modeli kullanılarak, incelenen 12 katlı yapı için SAP2000 paket programı ile MATLAB'te kodlanan yazılım eş zamanlı kullanılmıştır. Yapının zaman tanım alanında analizleri neticesinde hesaplanan yapı doğal titreşim periyotları, taban kesme kuvvetleri, 2 yönde kat ötelenme ve düsşey yer değiştirmeleri, kolon eksenel kuvvetleri, kolon eğilme momentleri, karşılaştırılmalı olarak sunulmaktadır.

\section{Problemin Matematik Modeli}

Geliştirilmiş Vlasov yöntemi kullanılarak modellenen elastik bir zemine oturan yapının temelinde oluşacak zemin tepkisi aşağıdaki gibi verilmektedir.

$q_{z}=-2 t \nabla^{2} w+k w$ 
Burada $w$ temelin düşey yer değiştirmesini göstermektedir. Bu ifadede yer alan $k$ yatak katsayısı, zeminin birinci parametresi olarak da adlandırılmakta ve

$$
k=\int_{0}^{H} \frac{E_{s}\left(1-v_{s}\right)}{\left(1+v_{s}\right)\left(1-2 v_{s}\right)}\left(\frac{\partial \varphi(z)}{\partial z}\right)^{2} d z
$$

ifadesi ile hesaplanmaktadır. Aynı ifadede bulunan $2 t$ ise zemin kayma parametresi olarak adlandırılmakta ve

$$
2 t=\int_{0}^{H} G_{s} \phi(z)^{2} d z
$$

ifadesinden hesaplanmaktadır. (2) ve (3) ifadelerinde $H, v_{s}$ ve $G_{s}$ sırasıyla elastik zemin derinliğini, zeminin Poisson oranını ve zeminin kayma modülünü göstermektedir. (1) nolu ifadede $2 t$ parametresi sıfır alındığında Winkler tipi elastik zemine oturan bir yapının temeline ait zemin tepkisi elde edilmektedir. Düşey yerdeğiştirmelerin derinlikle değişimi aşağıda verilen $\phi(\mathrm{z})$ fonksiyonu ile karakterize edilmektedir.

$\phi(z)=\frac{\sinh \gamma\left(1-\frac{z}{H}\right)}{\sinh \gamma}$

Bu ifadede yer alan zemin yüzey parametresi $\gamma$,

$$
\left(\frac{\gamma}{H}\right)^{2}=\frac{\left(1-2 v_{s}\right)}{2\left(1-v_{s}\right)} \frac{\int_{-\infty}^{+\infty} \int_{-\infty}^{+\infty}(\nabla w)^{2} d x d y}{\int_{-\infty}^{+\infty} \int_{-\infty}^{+\infty} w^{2} d x d y}
$$

ifadesiyle hesaplanmaktadır. $\phi(z)$ fonksiyonu plağın hemen altında 1 ve dikkate alınan zemin derinliğinin sonunda ise sıfır değerini almaktadır. Yani dikkate alınan elastik zemin tabakasının sonunda zeminin düşey yer değiştirmesi sıfır kabul edilirken temelin hemen altındaki düşey yer değiştirme temelin düşey yer değiştirmesine eşit alınmaktadır.

(2)-(5) ifadelerine bakıldığında zemin parametreleri, zemin malzeme özellikleri, zemin derinliği ve dış yüklere maruz yapının temel sisteminde oluşan düşey yer değiştirmeler arasında karmaşık bir ilişki görülmektedir. Yani zemin parametrelerinin hesaplanabilmesi için yer değiştirmelere ihtiyaç vardır ancak yer değiştirmeleri elde edebilmek için de zemin parametrelerini bilmek gerekir. Bu karmaşık ilişki bir ardışık yaklaşım yöntemiyle çözülebilir (Özgan 2007).

Bilindiği üzere Winkler tipi elastik zemin SAP2000 programında alan yayları kullanılarak analize dahil edilebilmektedir. Ancak bu durumda yaylar birbirinden ayrık davranmakta ve yaylar arasındaki etkileşim dikkate alınmamış olmaktadır. Bu çalışmada ise yaylar arasındaki etkileşimi sağlamak için yaylar ile temel arasına birim kalınlıkta sadece düşey yönde yer değiştirme serbestliği olan Shell-Layered/Nonlinear elaman tanımlanmıştır. Ayrıca Geliştirilmiş Vlasov modeline ait zemin parametrelerinin iteratif bir yöntemle hesabı için MATLAB ortamında bir arayüzü geliştirilmiştir. SAP2000-V16 içerisinde bulunan OAPI (Open Application Programming Interface) özelliği sayesinde bu arayüzde hesaplanan zemin parametreleri SAP2000 ortamına aktarılmış ve elde edilen yer değiştirmeler MATLAB ortamında yeniden kullanılmıştır. Zemin parametreleri istenen hassasiyetle yakınsayana kadar iki yönlü veri alışverişi ile iteratif işlem sürmektedir (Hamarat 2012). Çalışmada kullanılan yapıların SAP2000 modelleri Şekil 1'de ve hesap adımlarının akışı Şekil 2'de verilmektedir. Geliştirilen arayüz Kılıçer vd. (2014) tarafından bir radye temel örneği üzerinde doğrulanmıştır. Elde edilen sonuçlar literatürdeki sonuçlar ile uyum içerisindedir. 


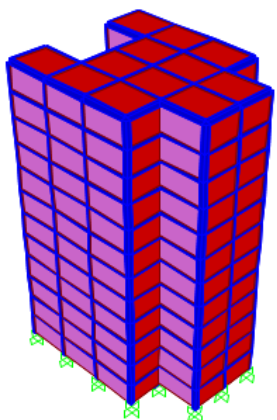

(a) Rijit temel

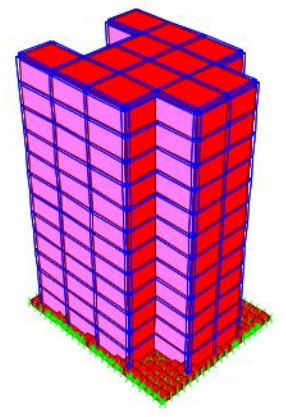

b) Winkler modeli

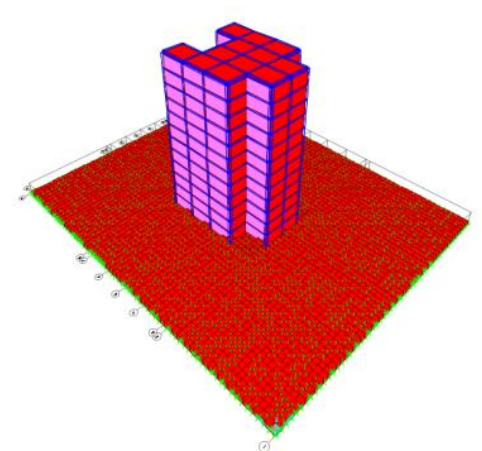

c) Geliştirilmiş Vlasov modeli

Şekil 1: Yapı modelleri

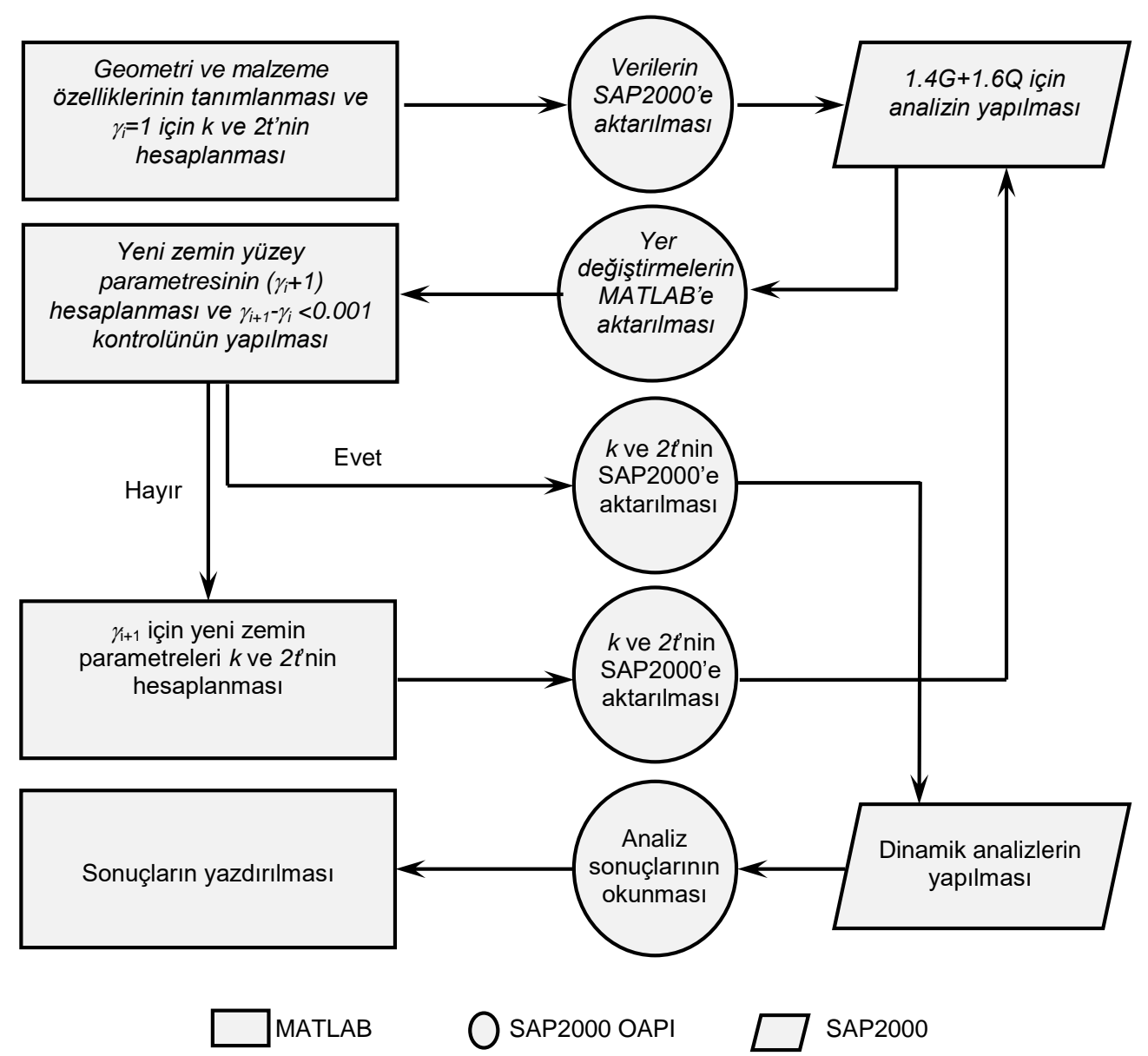

Şekil 2: Akış diyagramı

\section{Sayısal Uygulama}

Deprem etkisindeki bir betonarme yapıda yapı-zemin etkileşimini incelemek amacıyla 12 katlı betonarme bir yapı seçilmiştir. Yapının temeli $75 \mathrm{~cm}$ kalınlığına sahip radye plak olup boyutları $18 \mathrm{~m}$ x 22 m'dir. Tüm katların kat yükseklikleri eşit ve 2.7 m'dir. Yapıda kullanılan betonun elastisite modülü, Poisson oranı ve birim hacim ağırlığı sırasıyla $28 \mathrm{GPa}, 0.2$ ve $25 \mathrm{kN} / \mathrm{m}^{3}$ 'tür. Zeminin malzeme özellikleri $E_{\mathrm{s}}=50000 \mathrm{kN} / \mathrm{m}^{2}$ ve $v_{\mathrm{s}}=0.25$ olarak alınmıştır. Yapının oturduğu zemin $8 \mathrm{~m}$ derinlikten sonra bir kaya tabakası ile son bulmaktadır. Zemin sınıfı Z4 olarak düşünülmüştür. Tüm kirişler $30 \times 60 \mathrm{~cm}^{2}$ kesitine sahiptir. Düşey taşıyıcı elemanlar $50 \times 50 \mathrm{~cm}^{2}$ kolonlardan ve $30 \times 210 \mathrm{~cm}^{2}$ betonarme perdelerden oluşmaktadır. 
Bu uygulamada Winkler modelinde kullanılan yatak katsayısının $(k)$ ve Geliştirilmiş Vlasov modelinde kullanılan zemin özelliklerinin $\left(E_{\mathrm{s}}, v_{\mathrm{s}}\right)$ aynı zemin türünü temsil edecek şekilde seçilmesine özen gösterilmiştir. Zemin türü aynı olursa her iki modelden elde edilen sonuçları karşılaştırmak daha anlamlı olacaktır. Bu amaçla temel altı zeminin sıkı kum olduğu varsayılmıştır. Sıkı kum için Bowles (1982) tarafından verilen elastisite modülü ve zemin yatak katsayı değerleri Tablo 1'de belirtildiği gibidir. Tablodan görüldüğü gibi her iki parametre için alt ve üst sınırların aralığ çok geniştir. Bu aralıktan seçilecek her bir değer için farklı sonuçların elde edilmesi olasıdır. Bu uygulama da değerlerin alt sınırları olan $E_{\mathrm{s}}=50000 \mathrm{kN} / \mathrm{m}^{2}$ ve $k=64000 \mathrm{kN} / \mathrm{m}^{3}$ seçilerek gerekli analizler yapılmıştır.

Tablo 1: Sıkı kum için elastisite modülü ve zemin yatak katsayısı değerleri

\begin{tabular}{|c|c|c|}
\hline Zemin Cinsi & Zemin Elastisite Modülü (N/m²) & Zemin Yatak katsayısı $\left(\mathrm{kN} / \mathrm{m}^{3}\right)$ \\
\hline S1k1 Kum & $50000-81000$ & $64000-128000$ \\
\hline
\end{tabular}

Kalıp planı Şekil 3'de verilen yapının tüm kirişlerinin üzerinde birim hacim ağırlı̆̆ $5 \mathrm{kN} / \mathrm{m}^{3}$ olan gaz beton duvarlar vardır. Dış duvarların kalınlıkları $20 \mathrm{~cm}$ ve iç duvarların kalınlıkları $10 \mathrm{~cm}$ 'dir. Kat döşemeleri kirişli döşeme olup $2 \mathrm{kN} / \mathrm{m}^{2}$ hareketli yük etkisinde ve $15 \mathrm{~cm}$ kalınlığındadır.

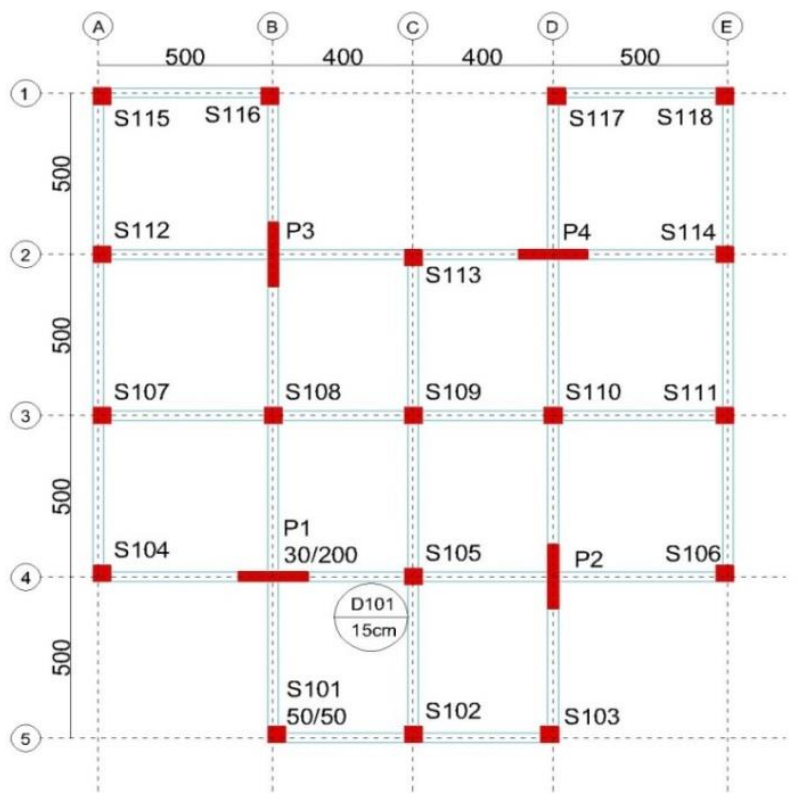

Şekil 3: Yapı örneğinin kalıp planı

Söz konusu yapının deprem hesabı Yarımca-Petkim (RSN 1176) istasyonunda kaydedilen 1999 Kocaeli Depremine ait ivme kayıtlarının doğu-batı ( $x$ yönü), kuzey-güney ( $y$ yönü) ve düşey ( $z$ yönü) yönündeki bileşenleri kullanılarak zaman tanım alanında hesap yöntemi ile 0.05 adım aralığında yapılmıştır. Depremin maksimum ivmeleri $0.33 \mathrm{~g}$ (K-G), $0.23 \mathrm{~g}$ (D-B) ve en büyük hız değerleri $85.68 \mathrm{~cm} / \mathrm{s}(\mathrm{K}-\mathrm{G}), 83.95 \mathrm{~cm} / \mathrm{s}$ (D-B) olup, depremin üç bileşenine ait ivme-zaman grafikleri sırasıyla Şekil 4, Şekil 5 ve Şekil 6'da verilmektedir.

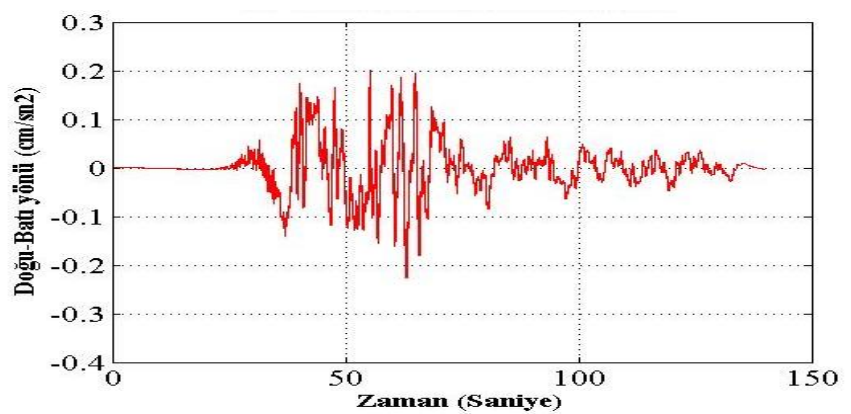

Şekil 4: Yarımca Petkim istasyonunda ölçülen 1999 Kocaeli Depremi doğu-batı yönü ivme-zaman grafiği (X yönü) 


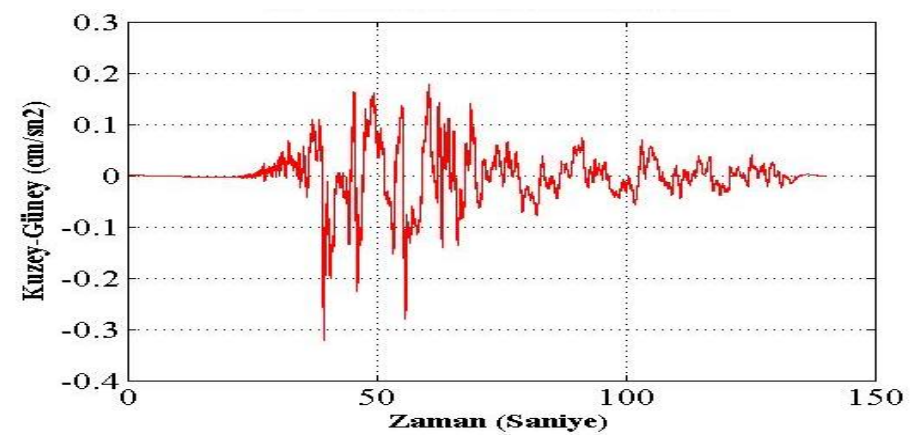

Şekil 5: Yarımca Petkim istasyonunda ölçülen 1999 Kocaeli Depremi kuzey-güney yönü ivme-zaman grafiği (Y yönü)

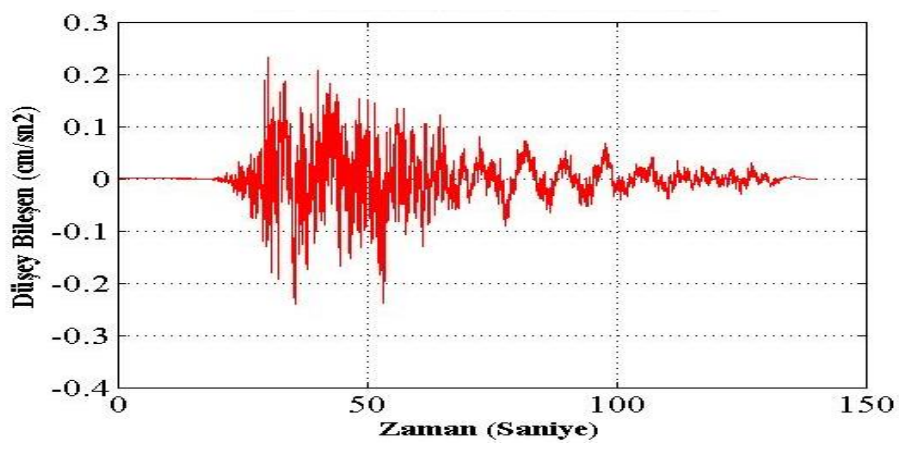

Şekil 6: Yarımca Petkim istasyonunda ölçülen 1999 Kocaeli Depremi düşey yönlü ivme-zaman grafiği (Z yönü)

Dinamik hesaplamalarda 1999 y1lında meydana gelen Marmara depreminin yapı-zemin sonlu eleman modellerinin tamamına aynı şiddette etki ettiği, sönümün \%5 olduğu ve zeminin lineer, izotrop ve homojen olduğu varsayılmıştır. $1.4 G+1.6 Q, G+Q+E_{\mathrm{x}}, G+Q+E_{\mathrm{y}}$ ve $G+Q+E_{\mathrm{z}}$ yük birleşimleri dikkate alınarak, rijit temel varsayımı, Winkler modeli ve Geliştirilmiş Vlasov modeli için ayrı ayrı analizler yapılmıştır. Yapının en alt kolonlarının deprem etkisi altında eksenel kuvvet ve eğilme momenti değişimleri her 3 durum için karşılaştırılmıştır. Ayrıca taban kesme kuvvetlerinin, yapı doğal titreşim periyotlarının ve S110 kolonun $x$ ve $y$ yönündeki yer değiştirmelerinin kat sayısı ile değişimi sunulmuştur. Deprem yer ivmesinin $y$ bileşeni $0.15 \mathrm{~g}, 0.33 \mathrm{~g}$ ve $0.45 \mathrm{~g}$ olacak şekilde değiştirilerek yapı kolonlarında meydana gelen moment değerlerinin zemin modelleriyle değişimi ayrıca incelenmiştir.

Yapı örneğinin her üç zemin modeline göre analizlerinden elde edilen ilk 12 moda karşılık gelen yapı doğal titreşim periyotları Şekil 7'de sunulmaktadır.

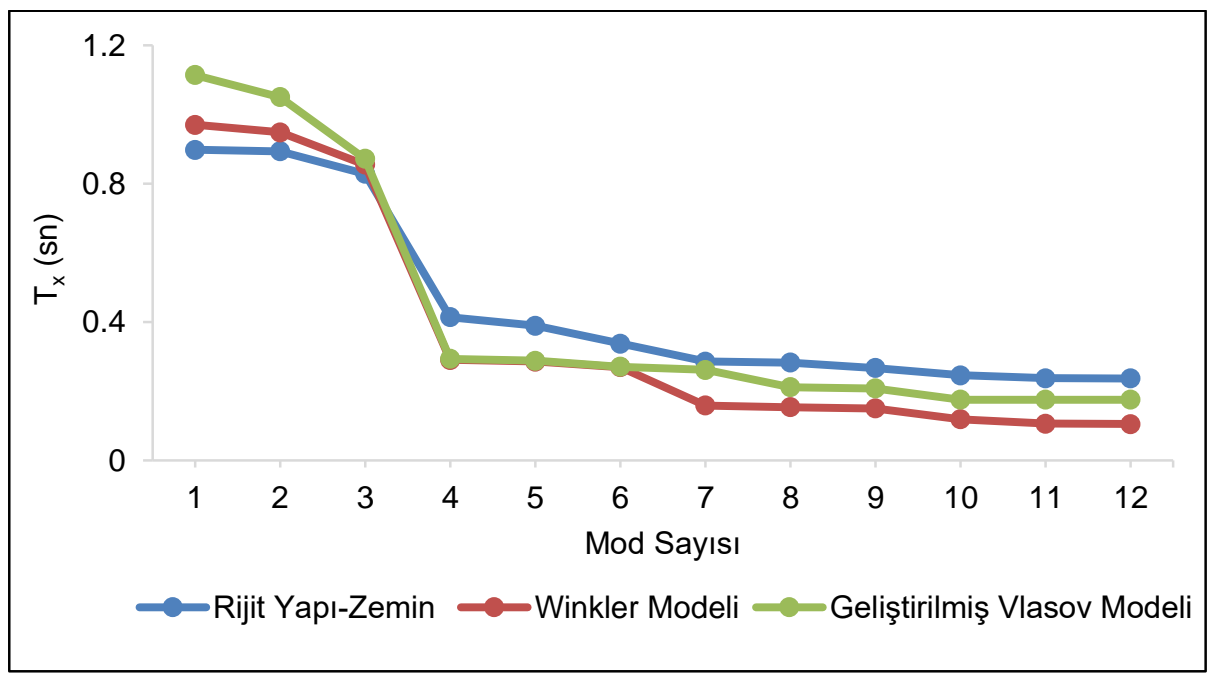

Şekil 7: Yapı doğal titreşim periyodunun zemin modellerine göre değişimi

Yapıların dinamik analizlerinde, meydana gelecek yatay kuvvetlerin hesabı için en büyük katkıyı 1. mod için elde edilen yapı doğal titreşim periyodu vermektedir. Bu sebeple ilk mod incelendiğinde sırasılyla en büyük periyot Geliştirilmiş Vlasov modeli, Winkler modeli ve rijit temel varsayımında meydana gelmektedir. 
7. mod'dan sonra periyot değerleri neredeyse yataylaşarak, tüm zemin modelleri için birbirine paralel hale gelmekte, değerinde ise önemli değişmeler görülmemektedir. Yapının taban kesme kuvveti, $G+Q+E_{\mathrm{x}}, G+Q+E_{\mathrm{y}}$ ve $G+Q+E_{\mathrm{z}}$ yük birleşimleri dikkate alınarak rijit temel (RT), Winkler (WM) ve Geliştirilmiş Vlasov modelleri (GVM) için karşılaştırılmıştır. Şekil 8'de verilen grafik göz önüne alındığında yapı örneğinde Geliştirilmiş Vlasov modeli dikkate alınarak yapılan çözümlerde taban kesme kuvvetlerinin oldukça büyüdüğü görülmektedir.

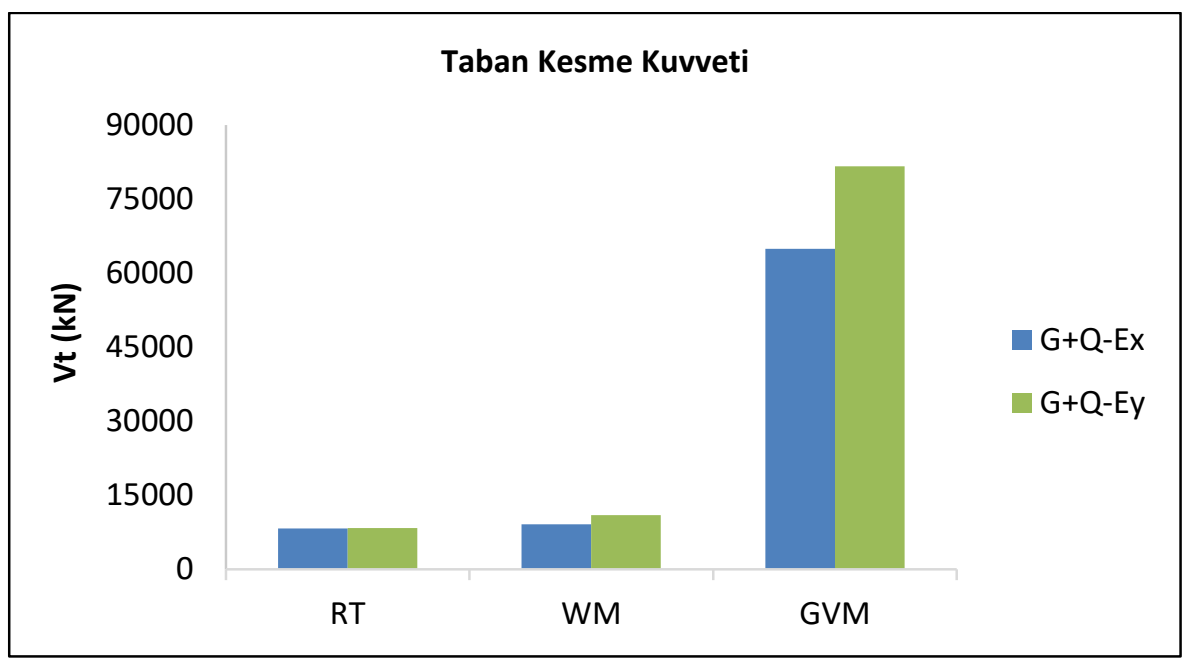

Şekil 8: Zemin modellerine göre taban kesme kuvvetinin değişimi

Her üç zemin varsayımında da $G+Q-E_{\text {y }}$ yük birleşimi için en büyük taban kesme kuvveti değerleri elde edilmiştir. Rijit temel varsayımında en küçük, Geliştirilmiş Vlasov modelinde ise en büyük taban kesme kuvvetleri hesaplanmıştır. Tüm yük birleşimleri için ayrı ayrı bakıldığında zemin etkisi taban kesme kuvvetlerinin artmasına neden olmuştur.

Depremin doğu-batı ve kuzey-güney bileşeni etkisinde S110 kolonunda $x$ ve $y$ yönünde oluşan yatay yer değiştirmelerin yapı yüksekliği ile değişimi Şekil 9'da belirtilmektedir.

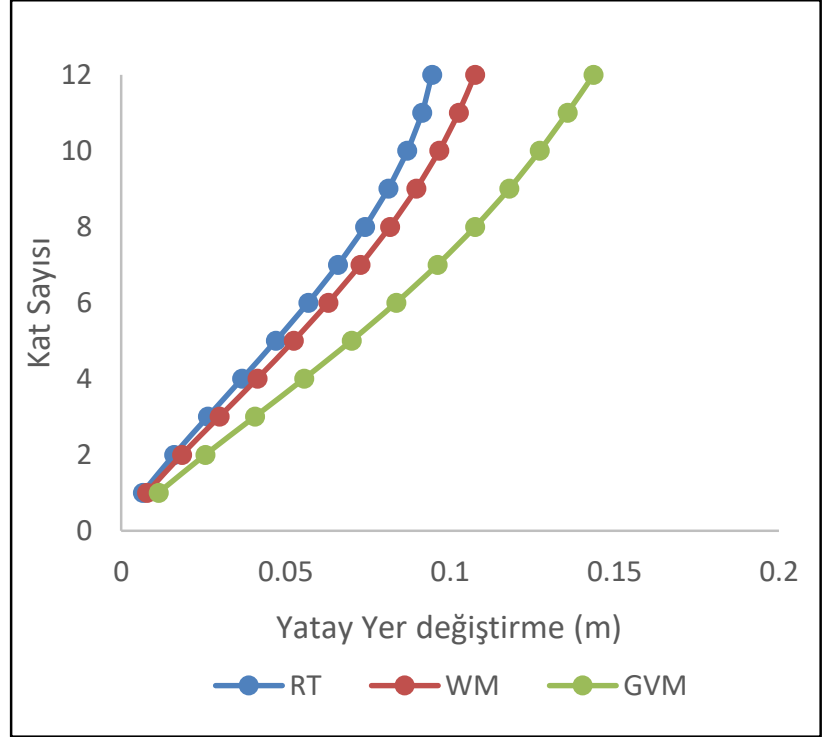

(a) $G+Q+E_{x}$

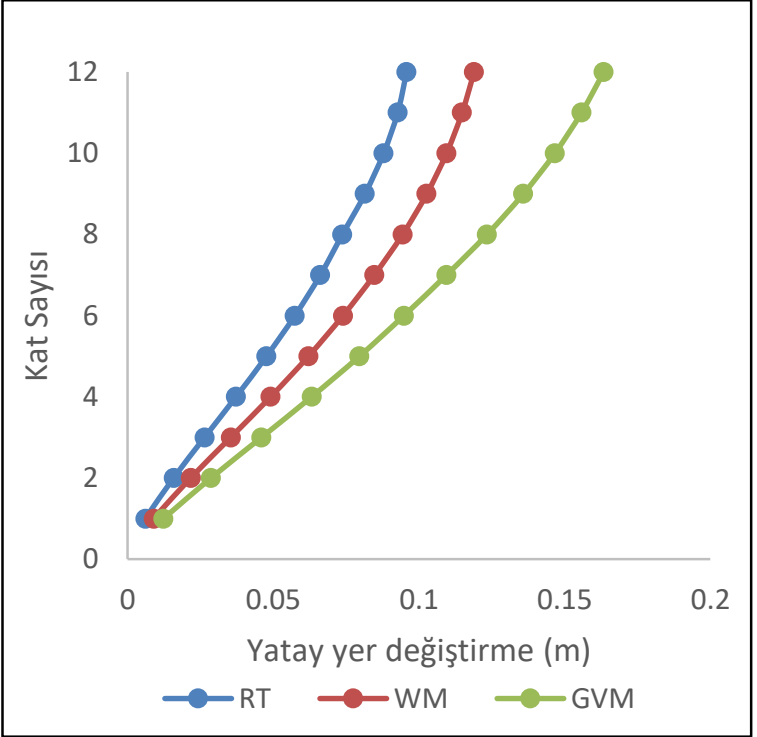

(b) $G+Q+E_{y}$

Şekil 9: Yatay yer değiştirmelerin S110 kolonu yüksekliği boyunca değişimi

Yukarıda bahsedildiği gibi depremin en büyük ivmesi kuzey-güney doğrultusunda $0.33 \mathrm{~g}$, doğu-batı doğrultusunda 0.23 g'dır. Yap1 y doğrultusunda (kuzey-güney doğrultusunda) daha büyük yer ivmesine maruz kaldığı için Şekil 9'dan da görüldüğü gibi yatay yer değiştirmeler bu doğrultuda daha fazla olmaktadır. Maksimum ivme değeri büyüdükçe farklı zemin modelleri için elde edilen yer değiştirmeler arasındaki farklar da artmakta ve kat seviyelerindeki yatay yer değiştirmeleri gösteren eğriler birbirinden ayrılmaktadır. 
Yap1 kuzey-güney doğrultusunda deprem bileşenine maruz bırakıldığında $G+Q+E_{y}$ yük birleşimi için zemin kat kolonlarında meydana gelen eksenel kuvvet ve eğilme momentleri ayrıca hesaplanmış ve Tablo 2'de verilmiştir. Eksenel kuvvet ve eğilme momentlerinin zemin modellerine göre değişimlerinin daha iyi anlaşılabilmesi için Şekil 10 ve Şekil 11 'de grafik halinde ayrıca sunulmaktadır.

Tablo 2: $G+Q+E_{y}$ yük birleşimi için kolonlarda elde edilen N-M değerleri

\begin{tabular}{|c|c|c|c|c|c|c|c|c|c|}
\hline \multirow{3}{*}{$\begin{array}{c}\text { Kolon } \\
\text { No }\end{array}$} & \multicolumn{9}{|c|}{ Kuzey- Güney Yönü (y yönü) } \\
\hline & \multicolumn{3}{|c|}{ Rijit temel varsayımı } & \multicolumn{3}{|c|}{ Winkler modeli } & \multicolumn{3}{|c|}{ Geliştirilmiş Vlasov modeli } \\
\hline & $\begin{array}{c}\mathrm{N} \\
(\mathrm{kN})\end{array}$ & $\begin{array}{c}\mathrm{M}_{\mathrm{y}} \\
(\mathrm{kNm})\end{array}$ & $\begin{array}{c}\mathrm{M}_{\mathrm{x}} \\
(\mathrm{kNm})\end{array}$ & $\begin{array}{c}\mathrm{N} \\
(\mathrm{kN})\end{array}$ & $\begin{array}{c}\mathrm{M}_{\mathrm{y}} \\
(\mathrm{kNm})\end{array}$ & $\begin{array}{c}\mathrm{M}_{\mathrm{x}} \\
(\mathrm{kNm})\end{array}$ & $\begin{array}{c}\mathrm{N} \\
(\mathrm{kN})\end{array}$ & $\begin{array}{c}\mathrm{M}_{\mathrm{y}} \\
(\mathrm{kNm})\end{array}$ & $\begin{array}{c}\mathrm{M}_{\mathrm{x}} \\
(\mathrm{kNm})\end{array}$ \\
\hline S101 & 674.37 & 356.45 & 5.68 & 863.86 & 557.20 & 23.49 & 1067.59 & 559.61 & 65.13 \\
\hline S102 & 578.88 & 469.89 & 8.27 & 713.97 & 553.17 & 27.47 & 751.30 & 527.89 & 52.63 \\
\hline S103 & 994.34 & 331.10 & 8.69 & 1148.41 & 574.69 & 102.48 & 1186.04 & 565.28 & 230.21 \\
\hline S104 & 269.55 & 464.14 & 4.27 & 378.40 & 629.73 & 34.18 & 482.23 & 687.28 & 57.29 \\
\hline S105 & 1505.41 & 540.59 & 2.93 & 1273.25 & 689.35 & 19.02 & 1014.29 & 696.48 & 32.71 \\
\hline S106 & 318.15 & 470.28 & 6.23 & 426.88 & 595.10 & 49.00 & 478.82 & 629.10 & 119.38 \\
\hline S107 & 1333.19 & 533.82 & 0.93 & 1317.05 & 718.89 & 26.59 & 1278.36 & 787.93 & 16.29 \\
\hline S108 & 1465.58 & 410.42 & 2.73 & 1526.23 & 762.01 & 21.39 & 1432.34 & 843.82 & 11.16 \\
\hline S109 & 1808.57 & 543.68 & 4.49 & 1767.30 & 752.58 & 34.21 & 1549.91 & 844.71 & 44.83 \\
\hline S110 & 1398.47 & 412.98 & 5.08 & 1570.54 & 755.40 & 17.70 & 1496.53 & 848.71 & 49.82 \\
\hline S111 & 1319.83 & 542.63 & 5.12 & 1306.34 & 705.81 & 13.18 & 1293.86 & 800.36 & 70.84 \\
\hline S112 & 1182.86 & 533.66 & 3.42 & 926.20 & 673.00 & 27.04 & 975.21 & 701.79 & 2.81 \\
\hline S113 & 238.63 & 475.67 & 4.18 & 201.69 & 660.49 & 23.03 & 331.92 & 765.50 & 28.02 \\
\hline S114 & 1126.33 & 543.74 & 3.80 & 866.71 & 691.63 & 1.13 & 889.76 & 803.17 & 45.44 \\
\hline S115 & 1285.44 & 467.97 & 9.24 & 1086.14 & 470.44 & 72.91 & 193.17 & 542.07 & 20.18 \\
\hline S116 & 1644.67 & 332.92 & 11.79 & 1568.22 & 555.72 & 103.12 & 487.80 & 659.39 & 147.13 \\
\hline S117 & 1173.64 & 362.72 & 10.35 & 1171.39 & 543.61 & 30.83 & 216.80 & 677.13 & 14.16 \\
\hline S118 & 1200.66 & 475.79 & 10.74 & 1012.51 & 473.10 & 30.50 & 296.40 & 588.17 & 0.88 \\
\hline
\end{tabular}

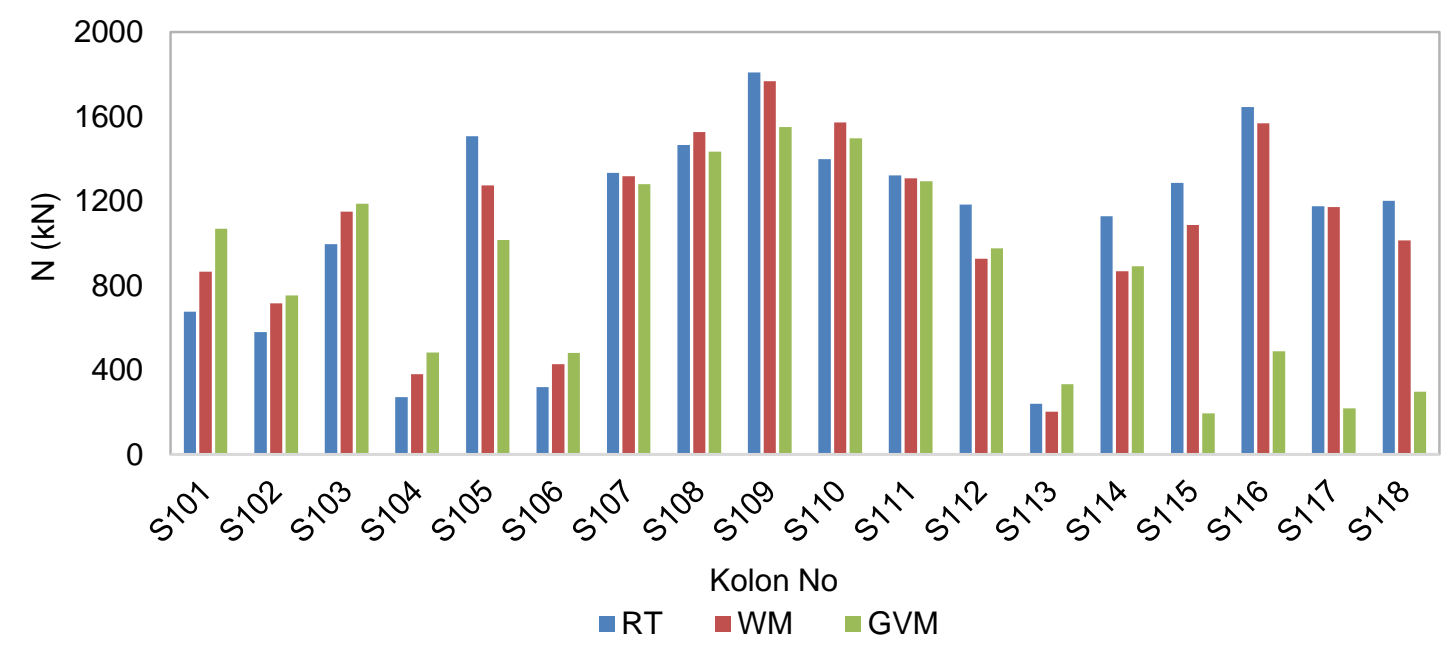

Şekil 10: Kolon eksenel kuvvetlerinin yapı zemin modeli ile değişimi

Şekilden de görüldüğü gibi herhangi bir zemin modeline göre yapılan çözümlerde kolon eksenel kuvvetlerinin daha büyük ya da daha küçük elde edildiğine dair genel yorumlara yol açabilecek sonuçlar elde edilmemiştir. Eksenel kuvvet, bazı kolonlarda rijit temel varsayımında fazla iken bazılarında da Geliştirilmiş Vlasov modelinde daha fazladır. Analizler sonucu taban kolonlarının y yönündeki eğilme momenti değerlinin daha büyük olduğu anlamıştır. Bu moment değerleri Şekil. 11'de verilmektedir. 


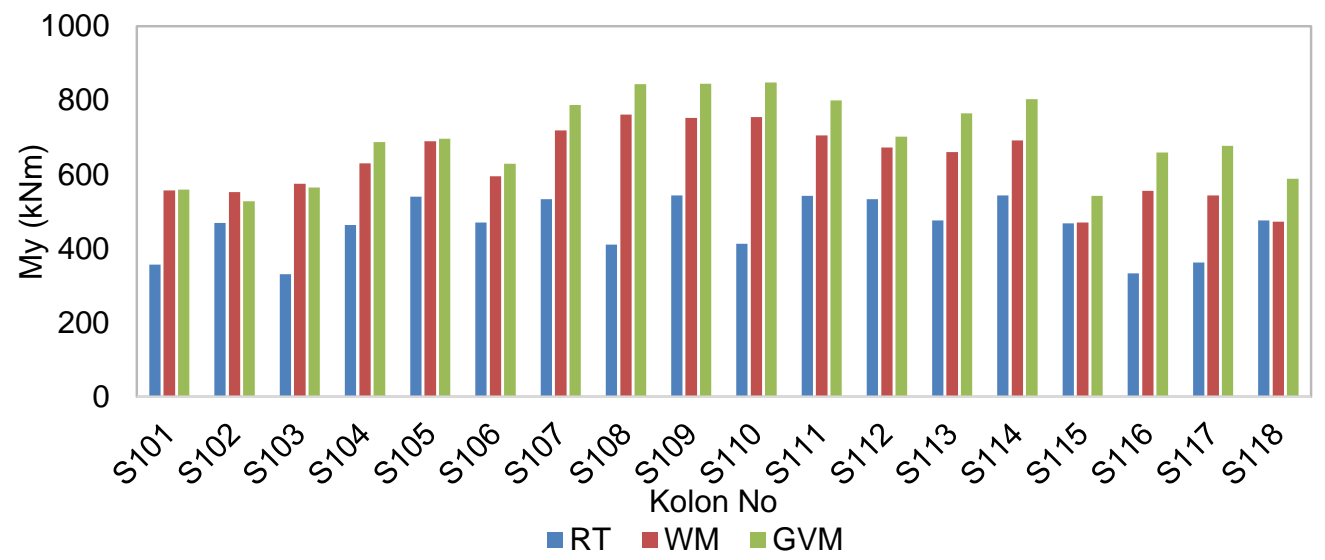

Şekil 11: Kolon eğilme momentlerinin zemin modellerine göre değişimi

$Y$ yönünde deprem ivmesine maruz yapının zemin kat kolonlarında zemin modellerine göre eğilme momentlerinde değişim oldukça fazladır. Hemen hemen her kolon, alt zeminin dikkate alındığı durumlarda rijit temel varsayımına göre daha büyük eğilme momentlerine maruz kalmaktadır. Rijit temel varsayımında en düşük eğilme momentleri elde edilmiştir. Üst yapının zemin ile birlikte dikkate alınmasının kolonların maruz kalacağı eğilme momentleri değerlerinin doğru hesaplanabilmesi için büyük öneme sahip olduğu Şekil 11'den anlaşılmaktadır. Ayrıca y yönündeki deprem ivmesi $0.15 \mathrm{~g}, 0.33 \mathrm{~g}$ ve $0.45 \mathrm{~g}$ olacak şekilde değiştirilerek analizler tekrarlanmış ve zemin kat kolonlarına ait her bir yer ivmesine karşılık gelen moment değişimleri, Winkler -Rijit yapı zemin modeli ve Geliştirilmiş Vlasov modeli- Rijit yapı-zemin modeli karşılaştırılarak Şekil 12 ve Şekil 13'de verilmiştir.

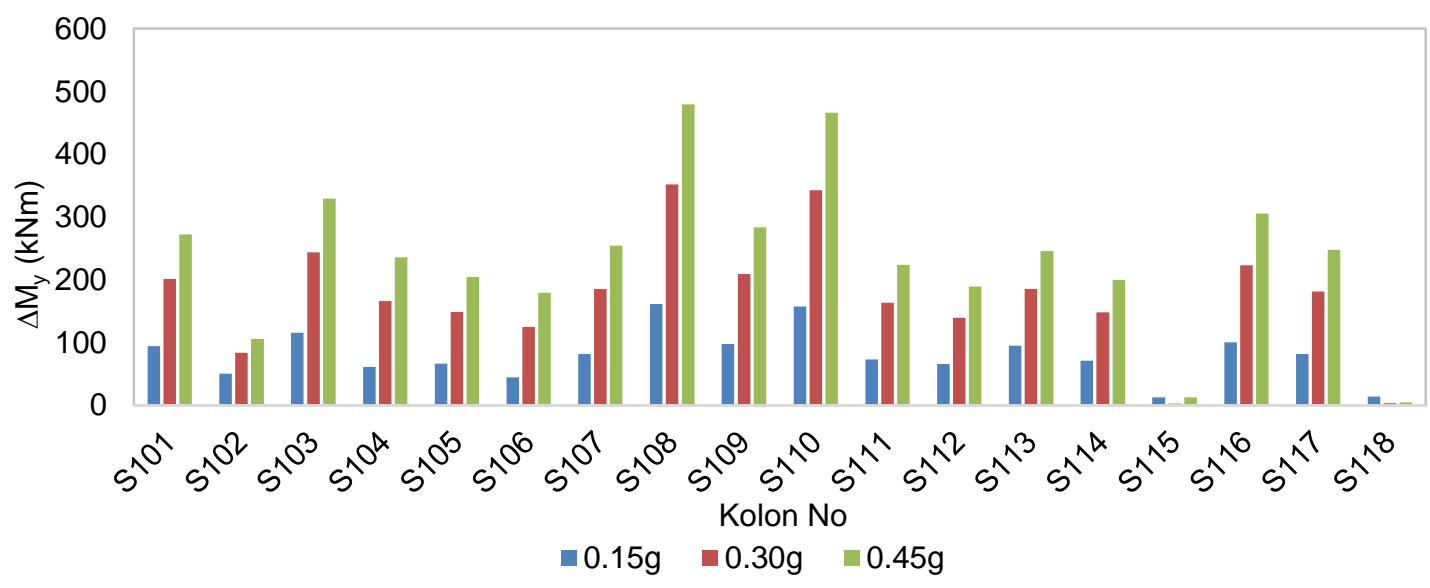

Şekil 12: Winkler modeli ile Rijit yapı-zemin modeli arasındaki moment değişimleri

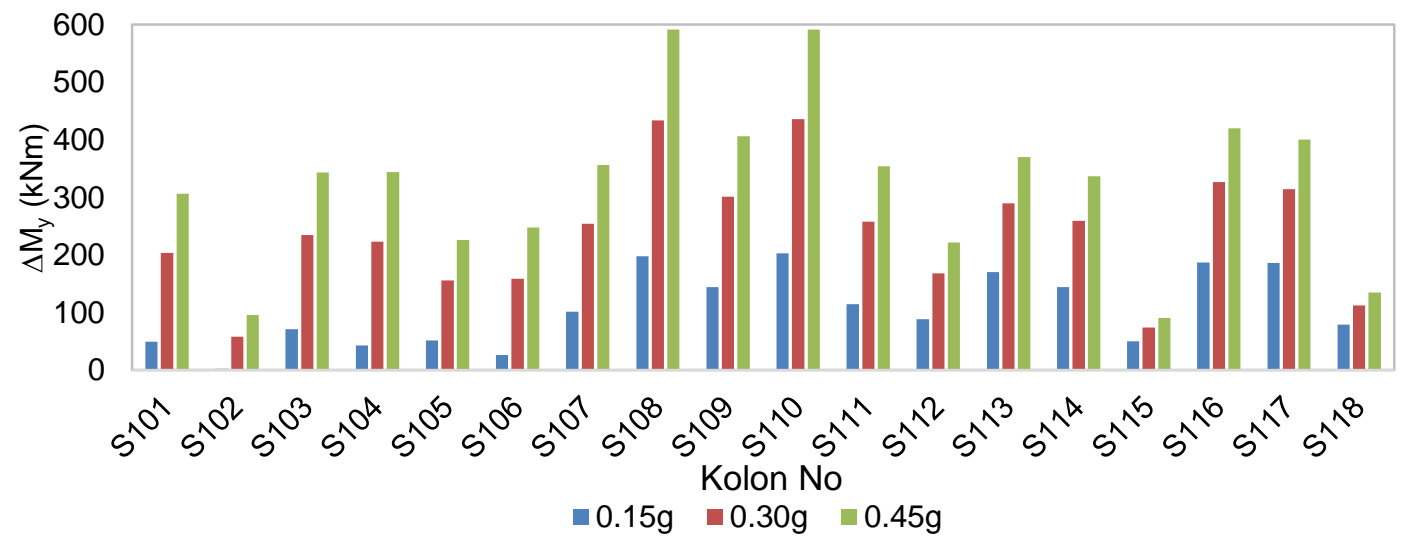

Şekil 13: Geliştirilmiş Vlasov modeli ile Rijit yapı-zemin modeli arasındaki moment değişimleri 
Şekil 12 ve Şekil 13'de görüldüğü gibi rijit temel varsayımı ile zemin etkilerinin dikkate alındığı modellerle yapılan analizlerden elde edilen momentler arasındaki fark deprem ivmesine bağlı olarak değişmektedir. $0.15 \mathrm{~g}$ yer ivmesi için rijit temel varsayımı ve elastik zemin modelleri arasında moment değerleri daha yakınken yer ivmesi büyüdükçe zemin modelleri arasındaki fark artmıştır. Şiddetli depremlere maruz kalan yapılarda zemin etkisinin daha da artacağı söylenebilir.

\section{Sonuçlar}

Bu çalışmada 12 katlı bir betonarme yapı oturduğu zeminle birlikte dikkate alınarak 17 Ağustos 1999 Kocaeli depremi etkisinde çözülmüştür. Yapının oturduğu zemin rijit temel varsayımı, Winkler modeli ve Geliştirilmiş Vlasov modelleri kullanılarak üç farklı şekilde modellenmiştir. Yapı-zemin sisteminin analizinde SAP2000 paket programı kullanılmıştır. Programa Geliştirilmiş Vlasov modeli ile çözüm yapma kabiliyeti kazandırmak için MATLAB'te kodlanan bir arayüz ile SAP2000 V16 programı eş zamanlı veri alışverişi yaptırılarak birlikte kullanılmıştır. Üst yapıdan zemine iletilen yükler ve zeminin malzeme özelliklerinden yararlanarak yatak katsayısı ve kayma parametresi belirlenmesi esasına dayanan bu zemin modeli ile yapı-zemin etkileşimi daha gerçekçi bir şekilde modellenmiştir.

Zemin etkilerinin yapının depreme karşı gösterebileceği davranışı anlayabilmek için en önemli parametrelerden biri olan doğal titreşim periyodu tüm zemin modelleri için farklı değerlere ulaşılmıştır. Yapının ilk modlarında Geliştirilmiş Vlasov modeli'nde daha büyük doğal titreşim periyodu değerlerine ulaşılmıştır.

Yapı kuzey-güney doğrultusunda, doğu batı doğrultusuna göre daha büyük yer ivmesine maruz kaldığı için yatay yer değiştirmeler beklenildiği gibi bu doğrultuda daha fazla elde edilmiştir. Maksimum ivme değeri büyüdükçe farklı zemin modelleri için elde edilen yer değiştirmeler arasındaki farklar da büyümüştür.

Kolon eksenel kuvvetleri de zemin modellerinde göre önemli farklıklar göstermişse de tüm kolonlar için genel bir yoruma ulaşacak sonuçlar elde edilmemiştir. Ancak kolon eğilme momentlerinde Geliştirilmiş Vlasov modelinde en büyük moment değerlerine ulaşılmıştır. Rijit yapı zemin modelinde ise en düşük eğilme momenti hesaplanmıştır.

Yapılara etkiyen deprem ivmeleri arttıkça sonuçlar üzerinde zemin etkisinin katkısı da artmaktadır. Özellikle şiddetli depremlerde yapı zemin etkileşimini göz ardı etmek yapı davranışında büyük değişimlere neden olabilmektedir.

Elde edilen sonuçlar incelendiğinde zemin etkisinin betonarme yapı taşıyıcı sistem tasarımında önemli rol oynadığ görülmüştür. Zemin-yapı etkileşiminin sadece temel tasarımını etkileyen bir unsur olmadığı, üst yapıda da önemli etkilere sahip olduğu unutulmamalıdır.

\section{Kaynaklar}

Avcıoğlu O., Orakdöğen E., (2015), Vlasov zeminine oturan yapıların zaman tanım alanında analizi, Pamukkale Üniversitesi Mühendislik Bilim Dergisi, 21 (3), 103-108.

Bowles E.J., (1982), Foundation analysis and design, McGraw-Hill Book Company, Newyork, 807ss.

Erdik M., (1989), Yüksek yapıların deprem tasarımında yapı-zemin etkileşimi ile ilgili esaslar, Çok Katlı Yapılar Sempozyumu, İzmir, Türkiye., ss.335-360.

Hamarat M.A., (2012), Íki parametreli zemin üzerine oturan yapı sistemlerinin dinamik analizi, Yüksek Lisans Tezi, İstanbul Teknik Üniversitesi, İstanbul, Türkiye.

Ionescu A., Calbureanu M., Negru M., (2013), Boussinesq method in seismic analysis of a building structure using ANSYS program, WSEAS International Conference, Vouliagmeni, Athens, Greece., ss.198-201.

Kilıçer S., (2016), Yapı-zemin etkileşiminin betonarme yapıların tasarımına etkisi, Yüksek Lisans Tezi, Karadeniz Teknik Üniversitesi, Trabzon, Türkiye.

Kılıçer S., Özgan K., Daloğlu A.T., (2014), Radye temellerin vlasov yöntemiyle modellenmesi, Zemin Mekaniği ve Temel Mühendisliği 2.Özel Konulu Sempozyumu: Teori ve Uygulamada Zemin-Yap1 Etkileşimi, Antalya, Türkiye., ss.151-156.

Livaoğlu R., Doğangün A., (2003), Farklı taşlyıcı sisteme sahip ayaklı depoların zemin sınıflarına göre dinamik davranışlarının irdelenmesi, Sakarya Üniversitesi Fen Bilimleri Enstitüsü Dergisi, 7(3), 70-77.

Özgan K., (2007), Geliştirilmiş vlasov modelini kullanarak elastik zemine oturan kalın plakların sonlu elemanlar yöntemiyle analizi ve etkin zemin derinliğinin belirlenmesi, Doktora Tezi, Karadeniz Teknik Üniversitesi, Trabzon, Türkiye.

Özgan K., Kılıçer S., Daloğlu A. T., Karakaş A. İ., (2016), Yapı zemin etkileşiminin betonarme yapıların tasarımına etkisi, Dokuz Eylül Üniversitesi Mühendislik Fakültesi Fen ve Mühendislik Dergisi, 18(53), 139-152.

URL-1, (2017), Deprem bölgelerinde yapılacak binalar hakkında yönetmelik, Resmi Gazete Tarihi: 06.03.2007, Resmi Gazete Sayıs1: 26454, http://www.mevzuat.gov.tr/Metin.Aspx?MevzuatKod=7.5.11162\&sourceXmlSearch=\&MevzuatIliski=0, [Erişim 10 Eylül 2017]. 